Sanjay Kalra ${ }^{1}$, Aravinda Jagadeesha ${ }^{2}$, Deepak Khandelwal ${ }^{3}$, Kirti Samudra ${ }^{4}$, Sharvil Gadve ${ }^{5}$, Supratik Bhattacharyya ${ }^{6}$

${ }^{1}$ Bharti Hospital, Karnal, Haryana, India

${ }^{2}$ Dr. Aravinda's Diabetes Centre Bengaluru, Karnataka, India

${ }^{3}$ Consultant Diabetologist and Endocrinologist Clinic, Delhi, India

${ }^{4}$ Diabetes Care Clinic, New Panvel, Maharashtra, India

${ }^{5}$ EXCEL Endocrine Centre, Diabetes Corner, Kolhapur, Maharashtra, India

${ }^{6}$ Apollo Clinic, Kolkata, India

\title{
Real-world experience of treatment individualization based on a fixed-dose combination of gliclazide extended release+ metformin extended-release in type 2 diabetes mellitus
}

\section{ABSTRACT}

Background. To evaluate the efficacy of gliclazide extended-release (XR) $60 \mathrm{mg}$ + metformin XR 500 $\mathrm{mg}$ fixed-dose combination (FDC) with metformin as an add-on (as needed) in real-world clinical practice. Methods. This prospective observational study was performed in patients with type 2 diabetes mellitus uncontrolled on metformin (group $M$ ) or on conventional gliclazide XR $60 \mathrm{mg}+$ metformin XR 500 $\mathrm{mg}$ (group GM), and newly diagnosed or untreated patients with $\mathrm{HbA1C}>9 \%$ (group U) at 6 out-patient diabetes care units. Patients received gliclazide XR $60 \mathrm{mg}+$ metformin XR $500 \mathrm{mg}$ FDC and metformin (as needed) at baseline for 30 days. Up-titration with gliclazide capped at $120 \mathrm{mg}$ and metformin every 30 days till day-90. The proportion of patients achieving target FPG was the primary endpoint.

Results. Of 455 patients (mean age: $51.9 \pm 11.3$ years; mean BMI $\left.26.7 \pm 6.2 \mathrm{~kg} / \mathrm{m}^{2}\right), 261$ patients had a family

Address for correspondence:

Sanjay Kalra

Bharti Hospital, Karnal, Haryana, India

e-mail: brideknl@gmail.com, drsanjaykalra2021@gmail.com

Clinical Diabetology 2021, 10; 2: 337-341

DOI: $10.5603 /$ DK.a2021.0042

Received: 30.09 .2020

Accepted: 28.12 .2020 history of diabetes and 161 patients had hypertension. Target FPG was achieved with 1 tablet each of gliclazide XR $60 \mathrm{mg}+$ metformin XR $500 \mathrm{mg}$ FDC and metformin by $73.09 \%, 74.26 \%$, and $60.66 \%$ patients in groups $M, G M$, and $U$, respectively. Only $29.23 \%$ of patients required up-titration to 1 tablet of FDC +2 tablets each of metformin and FDC at days 60 and 90 . Mean FPG, PPG and HbA1c significantly reduced at day-90 ( $P<0.001)$.

Conclusions. It can be concluded from this real-world primary-care practice study that the use of gliclazide XR 60 mg + metformin XR 500 mg FDC and metformin (as needed) was effective and well-tolerated, and $>3$ out of 5 patients achieved target glycaemic control within 30 days in all groups. (Clin Diabetol 2021; 10; 4: 337-341)

Key words: gliclazide, diabetes mellitus, metformin, glycaemic control, fixed-dose combination

\section{Introduction}

Diabetes has become a major healthcare issue imposing a huge economic burden, with about 77 million cases reported in India [1]. Evidence shows that most patients receive oral hypoglycaemic agents, but their poor adherence poses a major challenge in achieving glycaemic control. In Indian primary care 
settings, most patients are diagnosed and treated by general physicians and increasing the effectiveness of diabetes treatment at these centres has remained a priority. Most diabetes management guidelines recommend metformin-based dual drug combination to achieve target glycaemic control [2, 3]. Despite the availability of newer classes of antihyperglycemic agents, sulfonylureas (particularly gliclazide) have been commonly used in combination with metformin owing to its proven safety, efficacy, familiarity, guideline recommendations, cost and coverage [4]. A fixed-dose combination (FDC) of gliclazide extended-release (XR) $60 \mathrm{mg}$ plus (+) metformin XR $500 \mathrm{mg}$ is available in India as a scored and breakable tablet making its uptitration easier for better glycaemic control.

The present study aimed to assess glycaemic control in patients with type- 2 diabetes mellitus (T2DM) receiving gliclazide XR $60 \mathrm{mg}+$ metformin XR 500 mg FDC and metformin separately in addition, when required, in daily clinical practice.

\section{Material and methods}

This was a multi-centre, prospective observational study conducted between November 2017 and March 2018. The study was approved by a central ethics committee and all patients provided written informed consent. Patients with T2DM who received treatment per the clinical discretion of investigators as a part of routine clinical care with gliclazide XR $60 \mathrm{mg}+$ metformin XR $500 \mathrm{mg}$ FDC and add-on metformin XR $500 \mathrm{mg}$ (as per patient profile) were selected. These patients were categorized into three groups: newly diagnosed or untreated patients with $\mathrm{HbA} 1 \mathrm{c}>9 \%$ (Group U), those uncontrolled on metformin $500 \mathrm{mg}$ (Group M) and patients uncontrolled on conventional gliclazide XR 60 mg + metformin XR 500 mg (Group GM). Individuals who were pregnant or breastfeeding exhibited hypersensitive reaction to sulfonylureas, displayed severe hepatic or renal failure (creatinine clearance $<30 \mathrm{~mL} / \mathrm{min}$ ), demonstrated contraindication to gliclazide, presented with uncontrolled and clinically significant disease(s) or known malignancy or had a high probability of lost-to-follow-up, were excluded.

All patients were prescribed 1 tablet containing gliclazide XR $60 \mathrm{mg}$ + metformin XR $500 \mathrm{mg}$ FDC plus metformin $500 \mathrm{mg}$ (as per need) for 30 days at baseline. Treatments were up-titrated at the discretion of the investigators, based on fasting plasma glucose (FPG) levels measured at days 30,60 and 90. Dosing was capped at $120 \mathrm{mg}$ for gliclazide and $1500 \mathrm{mg}$ for metformin daily.

Data were collected from the patient's medical records maintained by the investigators. This included
Table 1. Demographic characteristics

\begin{tabular}{lc}
\hline Demographic characteristics of patients, $\mathbf{n}=455$ \\
\hline Age, years & $51.9(11.3)$ \\
Male & $244(53.6)$ \\
BMI, kg/m² & $26.7(6.2)$ \\
Systolic Blood Pressure, mm Hg & $132.5(15.7)$ \\
Diastolic Blood Pressure, mm Hg & $81.3(8.1)$ \\
Risk factors & \\
Smoking & $47(10.3)$ \\
Obesity & $137(30.1)$ \\
Clinical history & \\
Previous myocardial infarction & $20(4.4)$ \\
Previous congestive heart failure & $1(0.2)$ \\
Previous stroke & $4(0.9)$ \\
Family history of diabetes & $261(57.4)$ \\
History of other CVD & $45(9.9)$ \\
Hypertension & $161(35.4)$ \\
Dyslipidaemia & $103(22.6)$ \\
\hline
\end{tabular}

Data are shown as mean (SD) or n (\%); BMI: Body mass index; CVD: cardiovascular disease

baseline demographic and clinical characteristics. FPG and postprandial plasma glucose (PPG) levels were taken at baseline and days 30,60 and 90, and $\mathrm{HbA} 1 \mathrm{c}$ at baseline and at the end of study (day-90).

\section{Statistical analyses}

The primary endpoint was the number of patients achieving glycaemic control (FPG 90-130 mg/dL) on an intention to treat basis at follow-up visits in each group. Other endpoints were changes in FPG, PPG and $\mathrm{HbA} 1 \mathrm{c}$ from baseline at day 90 . Categorical data were presented as percentages with their $95 \% \mathrm{Cl}$, and changes in FPG along with their $95 \% \mathrm{Cl}$. Statistical analyses were conducted using SAS version 9.1.

\section{Results}

This study enrolled a total of 455 patients (group M: 197, group GM: 136 and group U: 122) at 6 centres across India. Patients had a mean age of $51.9 \pm 11.3$ years and a mean BMI of $26.7 \pm 6.2 \mathrm{~kg} / \mathrm{m}^{2}$ (Table 1 ). More than half $(\mathrm{n}=261)$ the patient population had a family history of diabetes, $35.4 \%(n=161)$ patients had hypertension, $30.1 \%(n=137)$ had obesity, $22.6 \%$ ( $n=103$ ) had dyslipidaemia and 9.9\% ( $n=45)$ had history of cardiovascular diseases.

Of 197 patients in group M, target FPG was achieved by $73.09 \%(n=144)$ with 1 tablet of gliclazide XR $60 \mathrm{mg}$ + metformin XR $500 \mathrm{mg}$ FDC plus 1 tablet 
of metformin at day-30 (Fig. 1A). About 15.29\% and $15.38 \%$ of patients received up-titration to 1 tablet of gliclazide XR $60 \mathrm{mg}+$ metformin XR $500 \mathrm{mg}$ FDC plus 2 tablets of metformin to achieve glycaemic control at day-60 and day-90, respectively. Only $5.90 \%$ and $6.41 \%$ of patients required 2 tablets of gliclazide XR $60 \mathrm{mg}+$ metformin XR $500 \mathrm{mg}$ FDC to achieve glycaemic control at day-60 and day-90, respectively (Figure 1A). Approximately $74.26 \%(n=101)$ patients in group $\mathrm{GM}$ achieved glycaemic control with gliclazide XR $60 \mathrm{mg}$ + metformin XR $500 \mathrm{mg}$ FDC plus 1 tablet of metformin at day-30; and approximately $12-15 \%$ required up-titration to 1 tablet of gliclazide XR 60 $\mathrm{mg}+$ metformin XR $500 \mathrm{mg}$ FDC plus 2 tablets of metformin at third and fourth follow-up visits. Only $0.87 \%$ patients required 2 tablets of gliclazide XR 60 $\mathrm{mg}+$ metformin XR $500 \mathrm{mg}$ FDC at day-60. None of the patients required 2 tablets of gliclazide XR $60 \mathrm{mg}$ + metformin XR $500 \mathrm{mg}$ FDC at day-90 (Fig. 1B). The proportion of patients who were newly diagnosed or untreated with $\mathrm{HbA} 1 \mathrm{c}>9 \%$ (group $U$ ) and achieved target FPG with 1 tablet of gliclazide XR $60 \mathrm{mg}+$ metformin XR $500 \mathrm{mg}$ FDC plus 1 tablet of metformin at day-30 was $60.66 \%(n=74)$. Around $12-14 \%$ of patients received up-titration to 1 tablet of gliclazide XR $60 \mathrm{mg}+$ metformin XR $500 \mathrm{mg}$ FDC plus 2 tablets of metformin at day-60 and day-90. About $12-19 \%$ of patients required 2 tablets of gliclazide XR $60 \mathrm{mg}+$ metformin XR $500 \mathrm{mg}$ FDC to achieve glycaemic control at days 60 and 90 (Fig. 1C). Collectively, the majority of patients achieved target FPG with 1 tablet of gliclazide XR 60 mg + metformin XR 500 mg FDC with 1 tablet of metformin at day-30 and only $29.23 \%$ (133/455) required the up-titration of treatment. Moreover, only a few patients remained uncontrolled at the end of the study across three groups (Fig. 1).

In patients uncontrolled on conventional gliclazide XR 60 mg + metformin XR 500 mg (group GM), mean FPG reduced from $159.85 \pm 39.12 \mathrm{mg} / \mathrm{dL}$ at baseline to $105.38 \pm 20.24 \mathrm{mg} / \mathrm{dL}$ at day-90 ( $<<0.001$; Figure $2 \mathrm{~A})$. Similarly, PPG decreased from $231.43 \pm 52.35 \mathrm{mg} / \mathrm{dL}$ to $162.19 \pm 26.4 \mathrm{mg} / \mathrm{dL}$ ( $\mathrm{P}<0.001$; Fig. $2 \mathrm{~B})$, and $\mathrm{HbA} 1 \mathrm{c}$ from $8.01 \pm 0.69 \%$ to $7.21 \pm 0.57 \%(P<0.001$; Fig. $2 \mathrm{C}$ ). In patients uncontrolled on metformin (group $M$ ), mean FPG was reduced from $168.12 \pm 37.21 \mathrm{mg} / \mathrm{dL}$ at baseline to $107.69 \pm 21.22 \mathrm{mg} / \mathrm{dL}$ at day-90 $(\mathrm{P}<$ 0.001 ; Figure 2A). Similarly, PPG decreased from 246.52 $\pm 63.27 \mathrm{mg} / \mathrm{dL}$ to $155.53 \pm 28.7 \mathrm{mg} / \mathrm{dL}(\mathrm{P}<0.001$; Figure $2 \mathrm{~B}$ ), and $\mathrm{HbA} 1 \mathrm{C}$ from $8.29 \pm 1.01 \%$ to $7.21 \pm$ $0.61 \mathrm{mg} / \mathrm{dL}$ ( $P<0.001$; Figure $2 \mathrm{C}$ ). In the last group of patients who are newly diagnosed or untreated with $\mathrm{HbA} 1 \mathrm{c}>9 \%$ (group $U$ ), mean FPG was reduced from $182.35 \pm 48.32 \mathrm{mg} / \mathrm{dL}$ at baseline to $109.45 \pm$

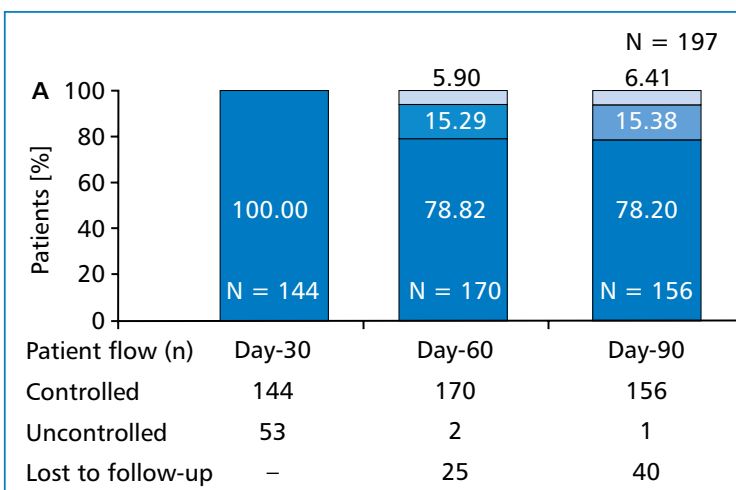

FDC of gliclazide + metformin $(1 \mathrm{tab})+$ metformin $(1 \mathrm{tab})$ FDC of gliclazide + metformin ( $1 \mathrm{tab})+$ metformin (2 tabs) FDC of gliclazide + metformin ( 2 tabs)

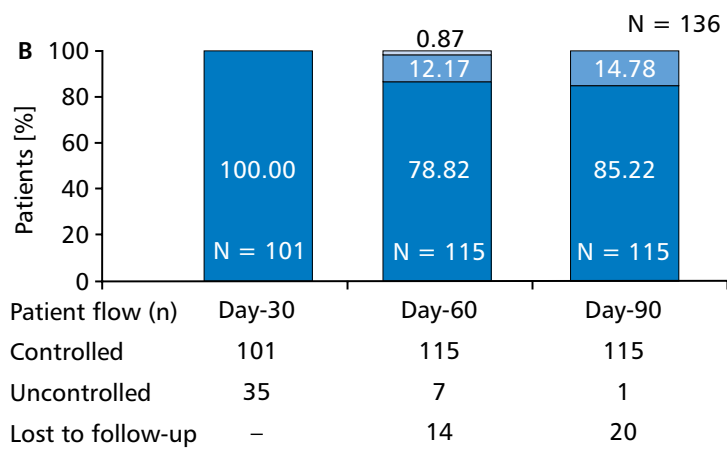

FDC of gliclazide + metformin (1 tab) + metformin (1 tab)

FDC of gliclazide + metformin ( 1 tab) + metformin ( 2 tabs)

$\square$ FDC of gliclazide + metformin ( 2 tabs)

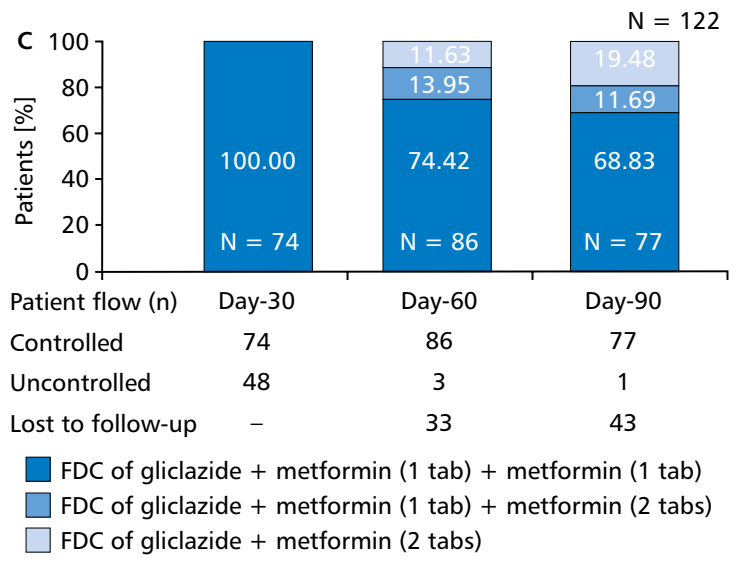

Figure 1. Glycaemic control rate and pattern of FDC use. The bar graph shows the pattern of FDC use in patients who achieved glycaemic control and the table represents the overall glycaemic control rate; A. Group M, patients uncontrolled on metformin $500 \mathrm{mg}(\mathrm{n}=197)$; B. Group $\mathrm{GM}$, patients uncontrolled on conventional gliclazide + metformin $(n=136)$; C. Group U, newly diagnosed or untreated patients with $\mathrm{HbA} 1 \mathrm{c}>9 \%(n=122)$

$18.79 \mathrm{mg} / \mathrm{dL}$ at day-90 ( $\mathrm{P}<0.001$; Fig. $2 \mathrm{~A}$ ). Similarly, PPG decreased from $267.2 \pm 67.32 \mathrm{mg} / \mathrm{dL}$ to 169.14 $\pm 25.62 \mathrm{mg} / \mathrm{dL}$ ( $\mathrm{P}<0.001$; Fig. $2 \mathrm{~B}$ ), and $\mathrm{HbA} 1 \mathrm{c}$ from $89.53 \pm 1.87 \%$ to $7.44 \pm 0.87 \%(P<0.001$; Fig. $2 C)$. 


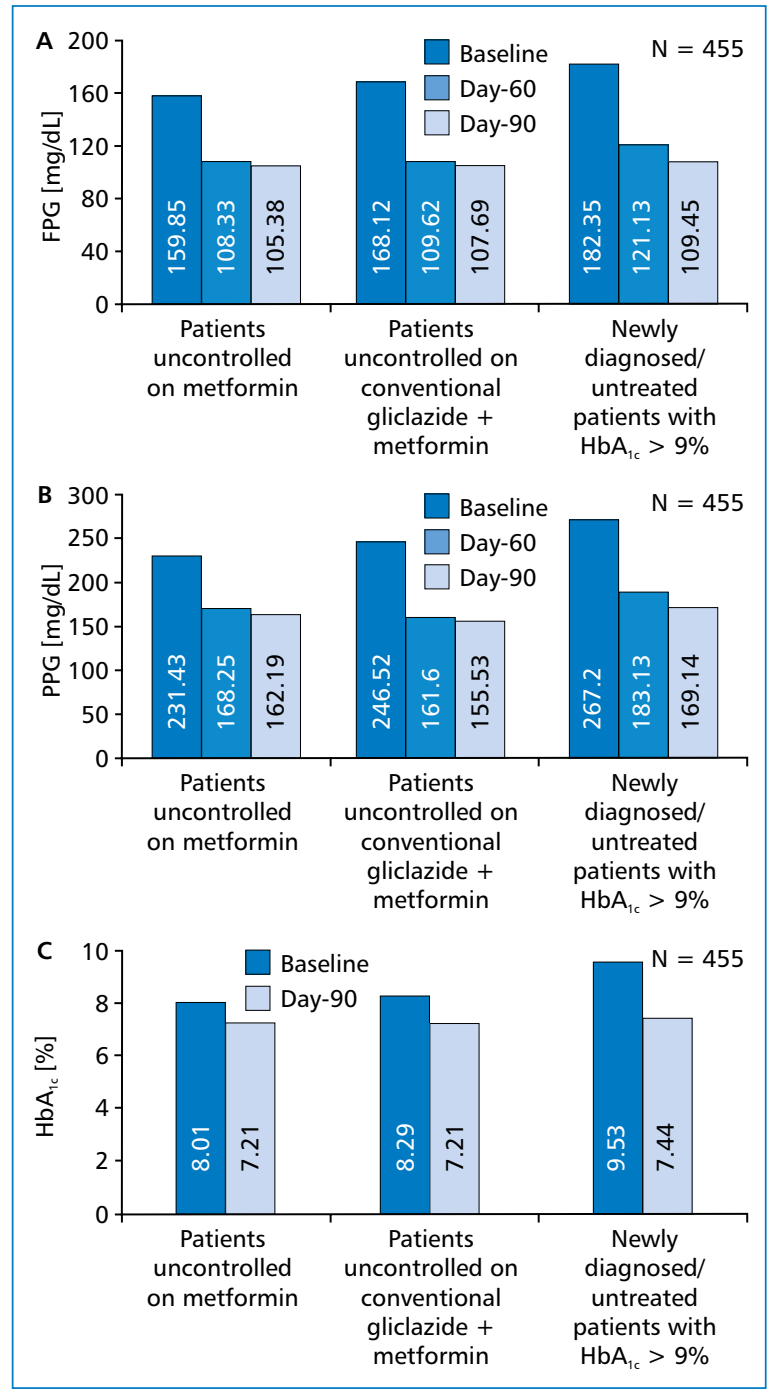

Figure 2. Glycaemic control in patients receiving the gliclazide XR $60 \mathrm{mg}+$ metformin XR $500 \mathrm{mg}$ and metformin XR 500 mg based up-titration; A: Mean FPG at baseline and follow-up visits; B: Mean PPG at baseline and follow-up visits; C: Mean $\mathrm{HbA} 1 \mathrm{c}$ at baseline and follow-up visits. FPG, PPG, and HbA1c were significantly reduced $(P<0.001)$ at Day-60 and Day-90 compared to respective baseline values; FPG: fasting plasma glucose; PPG: postprandial glucose

Overall, as expected, the decrease in glycaemic parameters were greater in Group U compared to Group M and Group GM. Altogether, the gliclazide XR $60 \mathrm{mg}$ and metformin XR 500 mg-based combination treatment, up-titrated at the discretion of physician for 3 months, significantly reduced FPG, PPG and HbA1c from baseline in all 3 patient categories.

\section{Discussion}

In this study, treatment of type 2 diabetes with gliclazide XR $60 \mathrm{mg}+$ metformin XR $500 \mathrm{mg}$ FDC and metformin-improved glycaemic control in all three groups. For patients who were uncontrolled on metformin alone or with conventional gliclazide XR $60 \mathrm{mg}$ + metformin XR $500 \mathrm{mg}$, approximately more than $50 \%$ of patients achieved target FPG within 30 days at the first visit. Moreover, about $37 \%$ of patients who were newly diagnosed or untreated, with $\mathrm{HbA} 1 \mathrm{c}>9 \%$, achieved target FPG by 30 days.

A line of evidence indicates that gliclazide reduces $\mathrm{HbA} 1 \mathrm{c}$ better than other insulinotropic agents [5]. Gliclazide is also cardio safe and has lower hypoglycaemia risk $[5,6]$. In the GUIDE (GIUcose control in type 2 diabetes: Diamicron MR vs glimEpiride) randomized, head-to-head trial, its hypoglycaemic risk was found to be lower compared to that of glimepiride [7]. A systematic review and meta-analysis of 18 studies including 1,67,327 patients with diabetes reported superior cardiovascular (CV) safety of gliclazide [6]. Danish registry of $1,07,806$ patients with diabetes with or without myocardial infarction who initiated singleagent treatment with insulin secretagogues or metformin, also showed lower CV and all-cause mortality risk with gliclazide at 9-year follow-up [8]. Similarly, in the Steno- 2 randomized trial conducted in 160 patients with diabetes, microalbuminuria, an intensive gliclazide therapy showed a median 7.9 years of life gain with + 8.1 years free from-CV-events at 21.2 years of median follow-up [9]. Unlike other SUs, greater selectivity of gliclazide for pancreas rather than myocardial sulfonylureas receptors, along with its fibrinolytic properties (which are independent of its glucose-lowering action) could be attributed to better CV safety [10].

Reductions in glycaemic parameters were in line with previously reported studies. Moreover, the results showing the feasibility and effectiveness of gliclazide XR $60 \mathrm{mg}+$ metformin XR $500 \mathrm{mg}$ FDC are in line with other studies conducted in India [11, 12].

Clinical practice guidelines including the latest WHO guidelines for diabetes management prefers gliclazide among other SUs, to be used with metformin as a combination therapy $[2,3]$. However, compliance to therapy remains a challenge. Treatment with FDC improves compliance and increases the probability of achieving target glycaemic control [13]. In this study, $>70 \%$ of patients achieved target FPG in a short duration and could explain the ease of up-titration using gliclazide XR $60 \mathrm{mg}$ + metformin XR $500 \mathrm{mg}$ FDC with metformin (when required). This could help all patient groups to achieve glycaemic control, faster.

A major limitation of this study is that patients did not receive randomized treatment. The medication regimen was at the discretion of prescribing physicians. However, these results represented the real-world primary-care practice data for efficient up-titration of 
the therapy using gliclazide XR $60 \mathrm{mg}+$ metformin XR $500 \mathrm{mg}$ FDC with metformin (as per patient profile).

Above all, the presented findings suggest that a gliclazide-metformin-based combination treatment, up-titrated at the discretion of physician for 3 months, significantly reduced FPG, PPG and HbA1c levels from baseline in patients either uncontrolled on metformin alone or conventional gliclazide XR $60 \mathrm{mg}+$ metformin XR $500 \mathrm{mg}$, and in newly diagnosed patients or untreated patients with $\mathrm{HbA} 1 \mathrm{c}>9 \%$. Overall, the treatment was well tolerated by the patients.

\section{Conclusion}

It can be concluded from this real-world primarycare practice study that efficient up-titration of therapy using gliclazide XR $60 \mathrm{mg}$ + metformin XR $500 \mathrm{mg}$ FDC plus metformin (as per individual patient need), can be an effective option to achieve optimal glycaemic control in daily clinical practice.

\section{Acknowledgements}

The authors would like to thank CBCC Global Research for providing scientific writing assistance in the development of this manuscript.

\section{Funding}

Serdia Pharmaceuticals (India) Pvt. Ltd. supported the conceptualization of the study and funded the scientific writing assistance for the development of this manuscript.

\section{Conflict of interest}

The authors declare no conflict of interest.

\section{REFERENCES}

1. International Diabetes Federation. IDF Diabetes Atlas 9th Edition. Brussels, Belgium: International Diabetes Federation 2019. http:// www.diabetesatlas.org

2. International Diabetes Federation. Recommendations For Managing Type 2 Diabetes In Primary Care, 2017. www.idf.org/ managing-type2-diabetes.
3. Garber AJ, Abrahamson MJ, Barzilay Jl, et al. Consensus statement by the American Association of Clinical Endocrinologists and American College of Endocrinology on the comprehensive type 2 diabetes management algorithm-2018 executive summary. Endocr Pract. 2018; 24(1): 91-120, doi: 10.4158/CS-2017-0153, indexed in Pubmed: 29368965.

4. Kalra S, Aamir AH, Raza A, et al. Place of sulfonylureas in the management of type 2 diabetes mellitus in South Asia: A consensus statement. Indian J Endocrinol Metab. 2015; 19(5): 577-596, doi: 10.4103/2230-8210.163171, indexed in Pubmed: 26425465.

5. Chan SP, Colagiuri S. Systematic review and meta-analysis of the efficacy and hypoglycemic safety of gliclazide versus other insulinotropic agents. Diabetes Res Clin Pract. 2015; 110(1): 75-81, doi: 10.1016/j.diabres.2015.07.002, indexed in Pubmed: 26361859.

6. Simpson S, Lee J, Choi S, et al. Mortality risk among sulfonylureas: a systematic review and network meta-analysis. The Lancet Diabetes \& Endocrinology. 2015; 3(1): 43-51, doi: 10.1016/ s2213-8587(14)70213-x.

7. Schernthaner G, Grimaldi A, Di Mario U, et al. GUIDE study: double-blind comparison of once-daily gliclazide MR and glimepiride in type 2 diabetic patients. Eur J Clin Invest. 2004; 34(8): 535-542, doi: 10.1111/j.1365-2362.2004.01381.x, indexed in Pubmed: 15305887.

8. Schramm TK, Gislason GH, Vaag A, et al. Mortality and cardiovascular risk associated with different insulin secretagogues compared with metformin in type 2 diabetes, with or without a previous myocardial infarction: a nationwide study. Eur Heart J. 2011; 32(15): 1900-1908, doi: 10.1093/eurheartj/ehr077, indexed in Pubmed: 21471135.

9. Gæde P, Oellgaard J, Carstensen B, et al. Years of life gained by multifactorial intervention in patients with type 2 diabetes mellitus and microalbuminuria: 21 years follow-up on the Steno-2 randomised trial. Diabetologia. 2016; 59(11): 2298-2307, doi: 10.1007/s00125-016-4065-6, indexed in Pubmed: 27531506.

10. De Fa. Evidence-based benefits of a selective secretagogue: Diamicron MR 60 mg. Medicographia. 2016; 38: 77-87.

11. Kalra S, Das AK. Epidemiologic Surveillance of Glycemic Response to a Scored, Breakable, Extended Release, Fixed Dose Combination of Gliclazide and Metformin in Persons with Type 2 Diabetes. J Assoc Physicians India. 2017; 65(6): 38-41, indexed in Pubmed: 28782312

12. Mohan V, Chopra V, Sanyal D, et al. Treatment of Type 2 Diabetes with a Breakable Extended Release Gliclazide Formulation in Primary Care: The Xrise Study. J Assoc Physicians India. 2015; 63(12): 26-29, indexed in Pubmed: 27666900.

13. Lavernia F, Adkins SE, Shubrook JH. Use of oral combination therapy for type 2 diabetes in primary care: Meeting individualized patient goals. Postgrad Med. 2015; 127(8): 808-817, doi: 10.1080/00325481.2015.1085293, indexed in Pubmed: 26439384. 